\title{
Correspondence
}

\section{Children and size of laryngeal masks}

To the Editor:

Selecting the correct sized laryngeal mask airway (LMA) is of utmost importance in determining the adequacy of oxygen delivery to a patient under anaesthesia. This seems especially so in paediatric cases where choosing a size according to the child's age may not necessarily be as accurate as a choice related to his/her body size. A wrong size can result in poor oxygenation.

A 12-yr-old boy was scheduled for urgent -exploration of testes to exclude torsion. His only past medical history was of mild asthma. On examination he looked chubby and large for his age. His maxilla and mandible were of normal shape and size. He weighed $45 \mathrm{~kg}$. Anaesthesia was induced with propofol, and a LMA size $\# 2-1 / 2$ inserted. The cuff was inflated with $14 \mathrm{ml}$ of air (as per manufacturer's guidelines) and satisfactory placement confirmed with gentle manual inflation of the reservoir bag on the Bain circuit. Anaesthesia was maintained with a nitrous oxide/oxygen/enflurane mixture. On commencement of spontaneous breathing chest expansion was satisfactory and movement of the reservoir bag good with no evidence of airway obstruction. Surgery was carried out uneventfully although the patient's oxygen saturation $\left(\mathrm{SpO}_{2}\right)$ was kept above $96 \%$ only by using a $50 /$ 50 oxygen/nitrous oxide mixture. Chest air entry and breath sounds were normal.

At the end of the procedure the boy was turned into the left lateral position and taken to the recovery area with the LMA in situ and inflated. Despite 100\% oxygen his $\mathrm{SpO}_{2}$ on the pulse oximeter was noted to be only $92-94 \%$. His general condition, respiratory rate, chest movement, air entry and breath sounds remained satisfactory. Air movement felt at the proximal end of the shaft of the LMA was also normal. The LMA was deflated and removed when he began objecting to its presence. An oxygen mask was placed over his face. Almost immediately his saturation rose to $100 \%$.

An explanation for the decrease in $\mathrm{SpO}_{2}$ was incorrect placement of the LMA. However, satisfactory positioning was checked throughout the procedure. A more probable explanation was of an inappropriately sized LMA resulting in a "leak" of anaesthetic mixture around the LMA cuff in the patient's laryngeal inlet with consequent decrease in oxygen delivery and resulting hypoxia. A large child of 12 would probably be more suited to a "small adult" size \#3 LMA.

Lawrence Chiew Hong Tham MBBS DA

Department of Anaesthesia

Freeman Hospital

Newcastle-upon-Tyne, NE7 7DN

England

\section{End tidal $\mathrm{O}_{2}$ and $\mathrm{CO}_{2}$ after resuscitation}

To the Editor:

Recently we continuously recorded the end tidal concentrations of oxygen $\left(\mathrm{PETO}_{2}\right)$ and carbon dioxide $\left(\mathrm{PETCO}_{2}\right)$ during cardiopulmonary resuscitation (CPR). A 67-yTold, $60-\mathrm{kg}, 167-\mathrm{cm}$ man underwent rectal resection under lumbar epidural plus sevoflurane anaesthesia. As his legs were placed from the lithotomy to the horizontal position, wide QRS waves followed by ventricular fibrillation (VF) were observed. External cardiac massage was instituted. The first counter-shock defibrillated the heart, but a few minutes later VF recurred ( $\mathrm{pH} 7.47, \mathrm{PaO}_{2} 511.2 \mathrm{mmHg}$, $\mathrm{PaCO}_{2} 19.6 \mathrm{mmHg}$, base deficit $6.2 \mathrm{mEq} \cdot \mathrm{L}^{-1}, \mathrm{~K}^{+} 6.8$ $\mathrm{mEq} \cdot \mathrm{L}^{-1}$ ). About $30 \mathrm{~min}$ later, an intra-aortic balloon pump (IABP) was instituted. Counter-shock was attempted about ten minutes after IABP, which resulted in arterial blood pressure of about $50 \mathrm{mmHg}, 50 \mathrm{~min}$ after the first VF (Figure), and defibrillating the heart. After the return of spontaneous circulation, the patient was able to maintain adequate blood gas status. Within the next five minutes he responded to verbal commands. Intraoperative fluid management appeared appropriate and the ECG and echocardiography recordings, and myocardial enzyme studies were all within the normal ranges. From the blood gas values a large air embolism appeared unlikely. A tentative diagnosis was made of coronary spasm or hyperkalaemia.

The respiratory gases were monitored by a Raman scattering spectrometer (Albion Co., United States) (Figure). The $\mathrm{PETCO}_{2}$ values have been considered as a good prognosticator of CPR in humans. ${ }^{1}$ The present recordings confirmed that $\mathrm{PETCO}_{2}$ about $15 \mathrm{mmHg}$ is a good indicator of successful CPR. ${ }^{2}$ The $\mathrm{PETCO}_{2}$ after the re- 


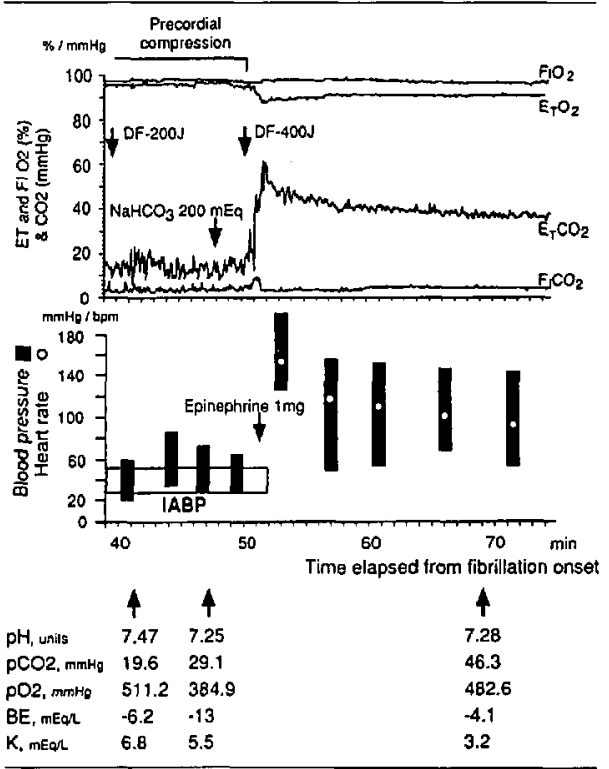

FIGURE

turn of spontaneous circulation consisted of accumulated $\mathrm{CO}_{2}, \mathrm{NaHCO}_{3}$ and partial rebreathing. ${ }^{1}$ In contrast, $\mathrm{PETO}_{2}$ has received little attention. ${ }^{3}$ In this case, the $\mathrm{O}_{2}$ uptake can be calculated approximately according to the equation: $\mathrm{VO}_{2}=600 \times(0.98-0.88) \times 10=600$ $\mathrm{ml} \cdot \mathrm{min}^{-1}$ which is almost one and a half or twice as much as the anticipated value. ${ }^{4}$ The large $\mathrm{FIO}_{2}-\mathrm{PerO}_{2}$ difference after the return of the circulation, was twice that occurring during CPR, and implies a large peripheral oxygen debt. An increase in oxygen uptake reflects resumption of pulmonary circulation as does $\mathrm{PETCO}_{2}$. In contrast to $\mathrm{PETCO}_{2}$, the $\mathrm{PETO}_{2}$ tracing is a smooth curve; therefore, the $\mathrm{PETCO}_{2}$ tracing is much easier to confurm the steady change. This change may be due to low blood solubility of $\mathrm{O}_{2}$ and thereby a rapid equilibration. Monitoring oxygen uptake could replace $\mathrm{PETCO}_{2}$ monitoring when the latter is not available.

Seiji Watanabe MD PhD,

Tetsu Kimura MD

Nobuaki Așakura MD

Department of Anesthesia,

Mito Saiseikai General Hospital

Royal Gift Foundation and Social Welfare Organization 3-3-10 Futabadai, Mito Ibaraki, 311-41 Japan

\section{REFERENCES}

1 Falk $J L$, Rackow $F C$, Weil $M H$. End-tidal carbon dioxide concentration during cardiopulmonary resuscitation. $\mathrm{N}$ Engl J Med 1988; 318: 607-11.

2 Gudipati CV, Weil MH, Bisera J, Deshmulkh $H G$, Rackow $E$. Expired carbon dioxide: a noninvasive monitor of cardiopulmonary resuscitation. Circulation 1988; 77 : 234-9.

3 Linko K, Paloheimo $M$. Inspiratory end-tidal oxygen content difference: a sensitive indicator of hypoventilation. Crit Care Med 1989; 17: 345-8.

4 Crone $R K$. The respiratory system. In: Gregory $\mathrm{G}$ (Ed.). Pediatric Anesthesia. New York: Churchill Livingstone, 1983, 54 .

\section{Malignant hyperthermia during isoflurane anaesthesia}

To the Editor:

A 15-yr-old, 58-kg male presented for surgical correction of thoracic kyphoscoliosis. He previously had had two uneventful operations under general anaesthesia where halothane, succinylcholine and enflurane had been used. Preoperative assessment revealed marked thoracic kyphoscoliosis. There was no family history of anaestheticrelated problems.

Diazepam $10 \mathrm{mg}$ was prescribed as premedication. Anaesthesia was induced with thiopentone $350 \mathrm{mg}$, fentanyl $100 \mu \mathrm{g}$, and pancuronium $8 \mathrm{mg}$ was given to facilitate tracheal intubation. Monitoring consisted of ECG, invasive measurement of arterial and central venous pressure, capnography, tidal volume, oxygen saturation, isoflurane concentrations, peripheral and core temperatures, neuromuscular transmission and urinary output. The patient's lungs were ventilated using a Drager Narkomed ventilator (semiclosed circle system). Anaesthesia was maintained with $30 \%$ oxygen in nitrous oxide and isoflurane $1-2 \%$ (Figure).

Labetalol $25 \mathrm{mg} \mathrm{iv}$ was given to maintain hypotensive anaesthesia. Four hours after induction, the end-tidal carbon dioxide concentration increased without any change in minute ventilation. Clinical examination of the patient's lungs was normal, and no faults were detected in the breathing system, ventilator or capnograph. Despite increasing the fresh gas flow and minute ventilation, the $\mathrm{PETCO}_{2}$ continued to increase. Arterial blood gas analysis confirmed a respiratory acidosis (Figure). The ECG was normal, and the arterial pressure remained stable. There was no cyanosis or sweating and oxygen saturations were $99 \%$. Rectal temperature increased from $35.5^{\circ} \mathrm{C}$ to $36.9^{\circ} \mathrm{C}$. A presumptive diagnosis of malignant 